\title{
Sustainable Supply of Wood for Musical Instruments
}

\section{Stanko Trifkovic ${ }^{\mathbf{a}^{*}}$

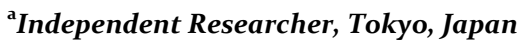 \\ Received: December 31, 2015/ Accepted: April 16, 2016}

\begin{abstract}
Wood traditionally used for soundboards of acoustic musical instruments such as violins or pianos is an exceptionally rare natural resource. Sustainability of its supply is not only faced with risks associated with long periods of growth but also with illegal logging and uncertainties linked with a change in the climate. Although the challenge to sustain supplies of resonance wood is certainly very high, sustainable supply of certain amounts of legally certified resonance wood is feasible. We will certainly lose a significant element of culture if we don't give a try to manage at least a few forest stands for the main purpose of producing this resonance wood.
\end{abstract}

Keywords:musical instruments; Balkans; resonance wood.

\section{Cultural heritage}

Wooden material traditionally used in acoustic musical instruments such as pianos or violins is usually referred to as resonance wood, resonant wood or tone wood. Also, classicalmusic loving folks sometimes call it amorously "singing timber". Resonance wood of an appealing quality to instrument makers, artists and finally the audience is today rarely found in forests. Its rarity can be seen partly in our harvest practices but also in our cultural heritage. "Sound and rhythm have been an intricate part of human nature, independent of region and culture"[1]. Different cultures in the past were continuously inventing new musical instruments, the majority were made with wood and their sound and shape were shaped primarily as a result of availability of the material but also in continuous efforts to please musicians and the audience [1].

Continuous efforts sometimes went-on to promote a use of material having very specific, often very rare, properties. At present, a high demand for resonance wood and its natural rarity drives its market price to amazing highs - this makes preserving our traditional ways of living (cultural sustainability), which still stands high on the agenda of most nations, very difficult to achieve.

\section{Resonant properties of wood}

Could it be that early merchants were selecting resonance wood by listening to the "song" [2] of rolling timber transported down from high mountain chains? Research is strong in claims that measuring acoustic or mechanical properties of wood can aid in selecting the "singing timber".

*orresponding Author

E-mail: stanko.trifkovic@live.com
Measuring the dynamic Young's modulus (stiffness of an elastic material) can distinguish between suitable and unsuitable wood material for sound boards for pianos[3]. Also, lower angles of cellulose microfibrils in wood cell walls of spruce trees result in higher Young's modulus and it is generally accepted that a reduction in the internal friction of wood improves the quality of soundboards[4]. However, comparison of wood specimens and evaluation of the resonance quality by assessing their physical and histological properties is not easy to conduct in practice, since the measurement conditions should be strictly controlled[5] and the measures are usually highly dependent upon the wood's moisture content [1]. All the above factors imply that selection of resonance wood is not an easy task. On the other hand, the practice of subjective quality grading, such as observing the annual ring structure of the wood from spruce used for soundboards of acoustic string instruments, could be sufficient to assess acoustic characteristics of the wood. Violin makers choose resonance wood mostly on the basis of their visual perception, whether it looks like "one that was successfully turned into a good musical instrument in the past" [6] as instrument makers "rely mainly on the art, knowledge, and experience passed on" [1] rather than on measuring acoustic or mechanical properties of the wood.

\section{Norway spruce}

Norway spruce or common spruce (PiceaabiesKarst.; hereafter spruce) is a traditional source of soundboards for acoustic musical instruments such as violins or pianos. Although the name suggests that it is a common species of the Scandinavian country, the natural distribution of spruce is wide in Europe. In the southern parts of Europe spruce natively grows in high mountain ranges and highland depressions where it can compete with other species withstanding harsh winters. Spruce is highly tolerant to frost and winter colds and it dominates in subalpine regions [7] or in valleys and other frost sites in high mountains [8]. In mountainous regions such as the Balkans, spruce naturally mix with other native species such as silver fir (Abies albaMill.; hereafter fir) and European beech (Fagussylvatica L.; hereafter beech). In such forests, where spruce successfully naturally regenerate, spruce trees can withstands premature dieback and reach their physiological age-limits [8].

\subsection{Forest stewardship}

It should be emphasized that governance used to be, and still is, one of the main factors affecting forest management. Also, forest management usually highly affects the distribution, composition and overall condition of forests. Wood from spruce is highly valued since it has a wide range of uses, thus forestry practices in the past increased its numbers [9]. But the results of the increase have typically resulted in uniform plantations highly susceptible to diseases and catastrophes, including those directly or indirectly caused by humans. Forest plantations are often managed in short rotations, so the trees are often harvested very young - too immature even to reproduce.

Foresters well know that mixed forests are usually a much more environmentally friendly option compared to uniform plantations. Trees in mixed forests usually naturally regenerate and create a stable system. Many cases can be found where a share of spruce trees in mixed-forests is too-high, but positive examples still exist. Large-dimension spruce trees and "remains of former virgin forests" still exist in the mountains of Bosnia [10]. That is partly due to the efforts and practice of a "close-to-nature" philosophy of forest management [11], due to the efforts given to 
preserve highly stocked forest areas [12], needs to preserve oldgrowth sites for a purpose of scientific research, or simply due to the lack of forest roads [13].

Bosnia Herzegovina, a country located in the heart of the Balkan peninsular is in many ways a representative case of the Balkans land and history. The unfortunate history of the land characterized by frequent wars has had a high, largely negative, influence to the forests. It can be assumed that forests in the Balkans have been utilized by man probably as early as other forests in Europe. Although governance by the Ottoman Empire in Bosnia and Herzegovina $(1463-1878)$ was characterized by a lack of infrastructure development, the Ottoman rulers regularly maintained trade with western countries in Europe and supplied them with valuable forest resources. For example, people of the city Dubrovnik managed to preserve their independence due to the established trade routes between the eastern Ottoman Empire and countries such as Austria and Italy. However, exploitation of forests from Bosnia in a large scale only started relatively recently during the governance of the Austria-Hungary Empire (1878 1914). It is recorded that a large amount of wood from Bosnia on the European market decreased its price, and in 1903 that caused an organized campaign of forest owners in Austria writing petitions to increase the price of wood [14]. The unfortunate history of the country and frequent wars in the last century further increased pressure on forests.

\subsection{Illegal logging}

In spite of a high pressure on natural resources, well-preserved forests where direct human influence such as harvesting of trees is not noticeable can still be found [15]. Several forest reserves in the Balkan's Dinaric Mountains still remain strictly protected - with the trees supposed to regenerate, grow and die without direct human influence. Unfortunately, illegal harvesting of trees has been identified recently in some of the forest reserves of Bosnia Herzegovina and it has been suggested that the illegal loggers are probably searching for resonance wood[16]. Some may state that the high price of resonance wood and the unfortunate history of the Balkan country have created conditions where the thieves can thrive. Some may blame it on unscrupulous elements in the musical-instruments' industry and their readiness to purchase illegally-logged trees. Therefore, it seems that any study regarding resonance wood can potentially be counterproductive as people with bad intentions can benefit. On the other hand, it is possible that a strong force decisive to protect forests for the benefit of future generations can still be recruited. Increasing people's awareness and sharing information is highly important in order to enhance protection of exceptionally valuable resources such as forests. On the other hand, covering-up the facts would only benefit the illegal-loggers.

When walking inside the forest reserve Lom, one of the strictly protected forest reserves in Bosnia, stumps scattered around on the forest floor can be noticed as remnants of the sawn-down large spruce trees once standing proudly in the forest. Some of the stumps were hidden by moss or covered in soil [16] but a careful eye can still notice that the hummocks are man-made. Some spruce trees were relatively recently harvested, while other stumps are already decayed to a greater or lesser extent (Figure 1). This observation suggests that a relatively long practice of illegal logging is taking a place in the forest which should legally be strictly protected. Standing spruce trees with chainsaw-madeholes in the trunks can also be noticed (Figurez). Such cuts could enable direct observation of the internal wood structure and are probably made by illegal-loggers in order to check whether the tree bears resonant wood or not. The harvested spruce tree (shown in the Figure 1.) with chain-saw-made holes along its trunk lies there on the forest floor like a reminder that not all of the old spruce trees are useful for the soundboards of violins or pianos. From the perspective of sustainability, the illegal harvest of the large spruce trees in forest reserves has been a crime of the worst kind, destroying the best genes from the resonance-wood bearing forest.

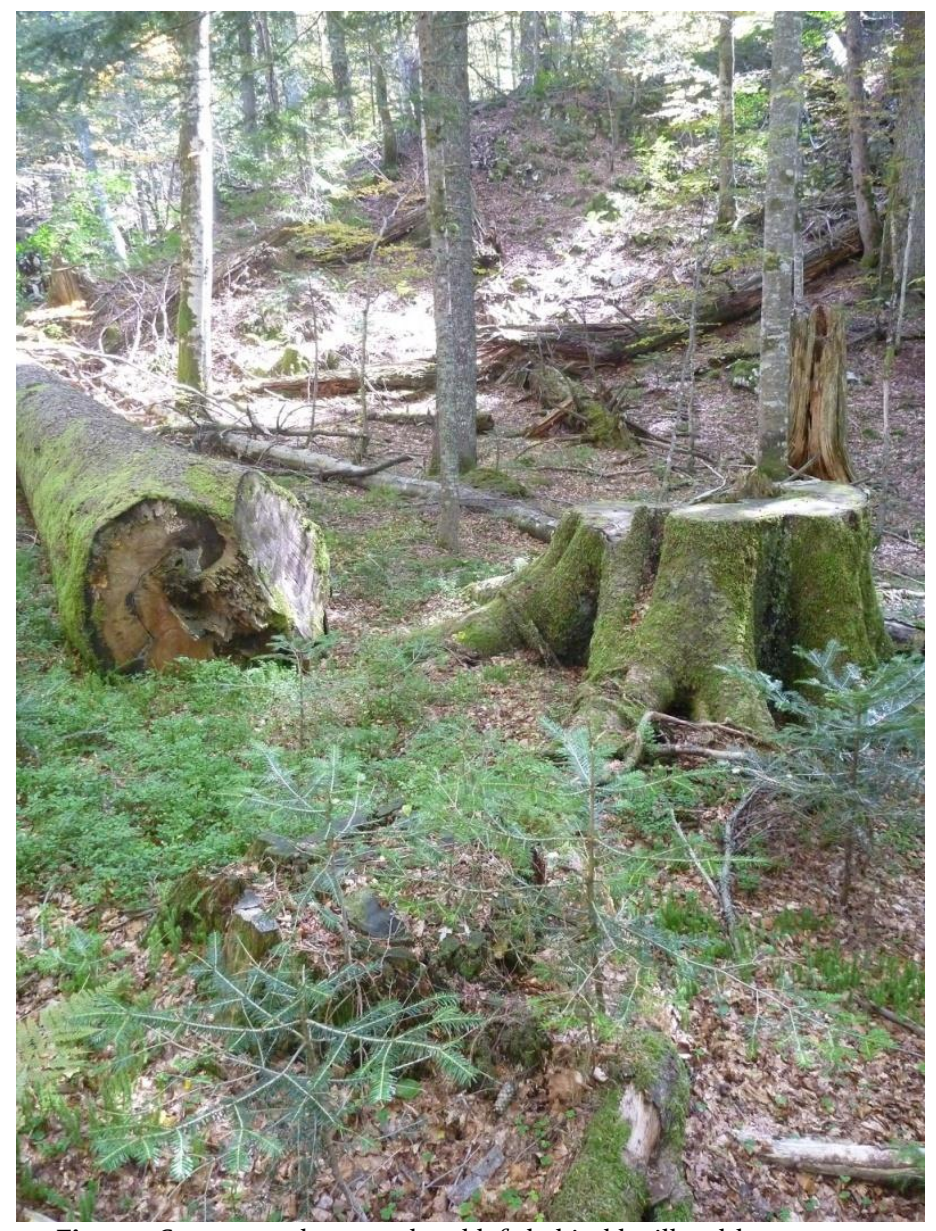

Figureı Spruce tree harvested and left-behind by illegal-loggers as a reminder that not every old tree is suitable for soundboards of traditional musical string instruments .Lower part of the photograph: A decayed stump suggesting that a relatively long practice of illegal-logging has been taking place at the forest reserve Lom

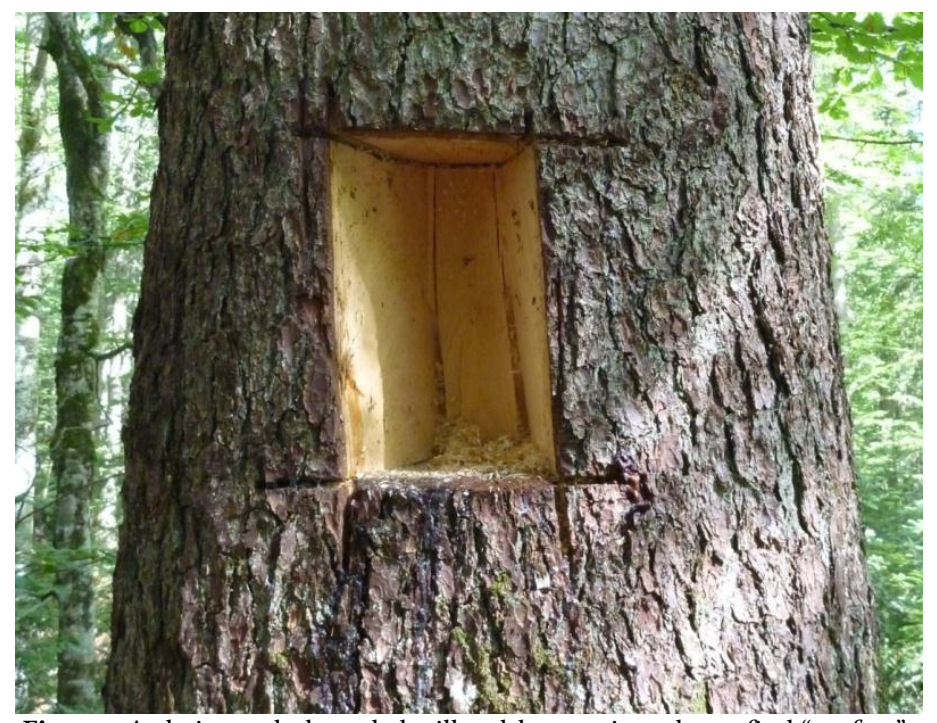

Figure2 A chainsaw-holemade by illegal-loggers in order to find "perfect" resonance wood. 


\section{What is the future of "wood culture"?}

A lack of high-quality resonance wood has already changed our habits, causing difficulties to preserve the cultural heritage associated with instrument manufacture. This is also a major factor inducing musical-instrument makers to shift toward new materials and approaches. Bond [17] has proposed to substitute traditionally used sycamore with tropical hardwood species muninga (Pterocarpuserinaceus Poir.) or mansonia (Sterculiacea $s p$.) in making the backs of violins even though wood such as mansonia is toxic with reported symptoms such as rhinitis, dermatitis or edema[18]. Today, the material for xylophone bars is almost entirely dependent upon tropical hardwoods [1] even though a rapid deforestation of tropical lands is still a concern. Many instrument makers, for example, have largely shifted toward the use of soundboards made from sitka spruce (Piceasitchensis (Bong.) Carr.). Small-angle cellulose microfibrils in the wood cell walls of sitka spruce may indicate its suitability for soundboards [19], but the main reason to use sitka spruce can be seen in the search by instrument makers to replace the traditional with more abundant material. Acoustic musical instruments made of laminated wood may also have good resonance properties [20]. Moreover, researchers have applied various approaches to improve resonance properties of wood such as using selected chemicals [21], retaining wood under high pressure and temperature [22] or utilizing a selected fungus [23]. The trend of altering or producing a completely new sound is also as old as our perception of music, so this is not necessarily unusual historically. There has also been a shift to completely substitute wood with materials such as aluminium or carbon fiber, or a shift toward electric (digital) instruments which mimic a sound but retain the playability of classical wooden-instruments (e.g. electric grand pianos). Although many would argue the better sustainability credentials of biomaterials - particularly grown biomass - it is questionable whether our "wood dependent culture" can persist into the future under these current pressures associated with growth in consumption. We can now enjoy the sound as well as the virtuosity of players and masterpieces they reproduce on electronic instruments. Our cultural legacy therefore does not necessarily be linked to a destruction and lust for rare specimens. Also, it is uncertain whether future high-end customers will insist on natural and traditional materials or some new materials, technologies or completely new musical instruments will replace the tradition.

\subsection{Climate, trees and the sound}

Wood from spruce suitable for soundboards of pianos should have annual ring widths of about 1 to $2 \mathrm{~mm}$ [3]. Usually, the growth of spruce trees is slower in subalpine than in mountain regions [24] and smaller annual-ring widths can be expected in colder climates if precipitation, soil quality and exposure to the sun for trees are approximately the same. This led to the hypothesis that Stradivarius, the old master from Cremona, was fortunate to live and work during a period of less-intense solar radiation in the Maunder Minimum, and thus had readily available material of higher quality than is available at present [25]. The variation in ring widths of wood used in soundboards in some old instruments can serve as an indicator of variation in temperatures in different growth seasons [26]. However, a low growth-rate of trees is not the only requirement for the best quality resonance wood. Ring widths should also be as uniformly distributed as possible since the wood from spruce having relatively high variation of annual ring widths is usually not regarded as a material having desirable resonance properties. In addition to the above, it is very important that the dimensions of the wood should be sufficiently large in order to be used in soundboards of acoustic musical instruments.

\subsection{Preserving the tradition}

It is believed that many consumers will still prefer owning a goodquality traditional musical instrument made from wood than to purchase its electric substitute. It is unlikely that they will support a depletion of forest resources. Such consumers whose purchasing power allows owning a high grade acoustic musical instrument should be increasingly interested in preservation of naturally scarce resources. Those who appreciate the sound of traditional instruments such as those made by Stradivarius or Guarneri [27] [28] [29], pitch and timbre of classic masterpieces [30], the visual appearance of wood such as its texture, grain pattern, and colour [1] or believe that "it is best not to modify the natural balance in the vibrational properties of wood, but to select a wood specimen of naturally high quality" [31] should pay more attention to sustain a supply of highly vulnerable forest products such as resonance wood while strictly protecting their natural sources. The concept of forest sustainability has evolved from that of "Sustainability of Yield" into a concept of multifunctional forestry, but still the tangible resources such as wood are high in demand. An increasing area of forests in wealthy nations is being managed for amenity purposes, since there is an "easy access to the cheap wood of the third world"[32]. It is hoped that this paper will reach the audience in economically leading centres and that they will begin a discussion and finally act toward establishing and strictly protecting forests having a potential to yield resonance wood in the future. The Balkans has a potential to yield resonance wood at present and it should receive attention immediately in order to achieve the goal of sustainability. Identifying, protecting and controlling a sustainable level of harvest is one vital factor.

\section{Resonant spruce: know-how}

Not everything about resonant spruce is clearly known. Much research is needed to grasp how to grow spruce trees in order to maximize the chance of producing "perfect" resonance wood. On the other hand, it can be claimed that the old masters from Cremona were fortunate to live in an age abundant with old spruce trees, making their chance of finding a "perfect" specimen much easier than it is for the musical instrument makers today. The example from the forest reserves in Bosnia teaches us that having the right forest at the right place can produce the best quality resonance wood from spruce if the forest is left undisturbed by man.

\subsection{Mixed forests}

A mixed-forest environment where the share of spruce trees is not excessively high will benefit spruce, protecting the individual trees against various disturbances, so the trees can reach their physiological limits [8]. The oldest age for spruce estimated from core data in the Lom reserve is around 440 years [33] and it is known that spruce hardly live longer than that. Management of forest resources is faced with many uncertainties as it may take 300 years or more for spruce trees to obtain the dimensions necessary to produce the required size for resonance wood. On the other hand, mixed forests are often less-susceptible to various disturbances, such as those caused by bark-beetles [34] or strong winds [35]. A mixed-composition of tree species may provide spruce with a protection against various disturbing factors, so the trees can obtain the dimensions large enough to produce resonance wood for soundboards of traditional musical instruments.

\subsection{Topography}

The topography of the Lom reserve is likely one of the reasons for its trees being less-exposed to strong winds. The Lom reserve is characterized by a micro-scale-disturbance regime with small gaps created by the natural dying process of single or very small groups 
of old trees [33]. Unlike in some subalpine regions where natural regeneration of spruce is not constant in time [36], larger gaps are not necessarily required for the spruce trees to regenerate, with the levels of establishment of spruce trees at the Lom reserve having been continuous during the past several centuries [37]. Spruce is a pioneer species but in its suitable frost sites in high mountains it also has properties of successive tree species [8].

Climate at the Balkan's Dinaric Mountains is largely influenced by the mountains themselves dividing the continental and Mediterranean areas. Furthermore, the Lom reserve faces north and has distinguished characteristics of the karst terrain where prevailing limestone bedrock is dissolved over thousands of years by running water creating many funnel-shaped depressions and hollows. High amounts of precipitated snow during winter remains in some of the depressions and deep hollows all the yearlong. The cooling effect of such "natural freezers" may benefit regeneration and influence the growth of spruce trees. Geomorphology of the karst terrain during winters also influences the prevailing vegetation and composition of forests since the depressions and sinkholes "trap" the cold air and in some places, for example at the depression Mrazište at Igman Mountain, the temperatures measured in winter often fall below $-40^{\circ} \mathrm{C}$. All these factors suggests that terrain conditions reassembling those at the Lom reserve are an important factor responsible for bearing highquality resonance wood from spruce.

\subsection{Disturbance}

It is likely that untouched forest reserves hold more potential to bear resonance wood than their counterparts frequently disturbed by chainsaws. A disturbance regime involving larger gaps will not favour uniform growth rates. Strong winds do not play a significant role in gap-making at the Lom reserve [37] as they do in some other spruce stands [35]. At strictly protected forest sites, suitable for spruce to naturally regenerate and to grow in equilibrium with beech and fir, naturally occurring processes like birth and death of individual trees are unlikely to highly disturb the internal stand balance and competition between the trees. Thus the equilibrium inside the Lom forest reserve where the new naturally regenerated spruce seedlings sprout and old trees die all the time without large disturbances is found to be one of the most important prerequisites for the growth of high-quality resonance wood.

\subsection{Allowing the trees to grow old}

The majority of trees at the Lom reserve have grown suppressed by the upper-storey trees during their juvenile stages [33]. This is typical in mountainous forests where beech, fir and spruce naturally mix. Hence the wood from spruce grown in mixed forests often exhibit a pattern of growth rings with the central part of the trees highly influenced by a very slow growth during the juvenile stage, when often decades are spent in the shaded understory layers. Reaching the upper storey, the trees accelerate the gain in their diameter increment rates and apparently the wood material from the trees exhibiting such variation in its internal structure is not favoured for use in acoustic musical instruments. However, such pattern in the diameter growth is not likely to be exhibited in wood grown a bit higher above the ground. Thus wooden parts from spruce trees clear of branches, with a straight shape, untwisted grain and grown slightly higher above the ground are more likely to yield high-quality resonance wood if the necessary size for making acoustic instruments is met.

Clearly, forest management has done a very little to ensure that supplies of resonance wood are sustainable. Resonance wood of naturally high quality is very rare in forests being the subject of current forest management practices which heavily favouring the "industrial production of wood" with trees having higher growth rates. The only way for the trees to reach the necessary size is to let them get old. The slow rate of required growth - and the long time lag until maturity - make the consideration of intergenerational benefits and equity highly important, as the person who watch over the tree seedlings now will be less likely to obtain benefit directly from their harvesting.

\section{Future of forest reserves in Bosnia}

In aftermath of the recent war in Bosnia Herzegovina (1992-1995) one of the largest forest reserves in Europe, forest reserve Peručica, almost lost its special protected status. Fortunately, the area remained intact thanks to the foresters guarding the area and informing the government that the utilization of the reserve would require investment into the roads and other infrastructure and that it would be impossible to return the investment in a short timeframe. Forests far from roads and the mainstream of forest management are likely to remain untouched and retain their status of "virgin forest". Although thieves may have taken the best spruce trees from the forest reserve Lom, it is believed that the forest will recover itself if its protection against such theft is adequately conducted from now on. Protection of current forest reserves should be enhanced to ensure this. The question is how to adequately protect the forest reserves if their alluring tangible resources are located relatively near to road infrastructure? Another question, even more difficult to answer, is whether the officials in Bosnia Herzegovina are interested in continuing the enforcement of a complete ban of harvest in forests entirely purposed for scientific research? This resource is priceless for scientists to study the development of untouched forests. However the economy of the country driven by immediate gains may not recognize gains given by science which often comes in the very long-term. So the extension to the question above would be whether the governing system in Bosnia Herzegovina is interested to fund projects whose benefits in terms of the economy are very far from reach?

It is believed that majority of the foresters in the Balkans long to pass their forests on to future generations in good shape continuing to provide society with multiple goods and benefits. However, in societies in transition conflicts may arise when local people and governments cannot realize the importance of protecting forest reserves and thus illegal exploitation of forests may escalate. Economical indices suggest that Bosnia Herzegovina is a country which heavily depends upon the export of wood. Its geographical proximity to European industrial centres, and the hearts of violin and piano culture, makes Bosnian forests even more vulnerable. Many people in Bosnia play and enjoy classical music but it is questionable whether the vast majority see the importance in protecting the assets of a culture which so heavily depends on rare natural resources. Also, it is uncertain whether highly-valued resonance wood today will be so highly-valued in the future, neither do we know how changes in the Earth's climate will affect the growth of spruce trees. All these questions may suggest that it is economically justified for foresters to cut and sell these valuable products now, as soon as they can, to obtain a high profit. Something clearly needs to be done and it needs to be done as soon as possible in order to adequately protect forest reserves in Bosnia Herzegovina. Forest reserves in the Balkans have a great potential to attract many visitors, and they should continue serving as research sites and for educational purposes and not as a supply of illegally-logged resonance wood.

With pressure from the general public on the industry in order to cease production lines using illegally harvested trees, it is believed that the illegal-logging of the trees in forest reserves can be reduced, but not completely stopped. Securing a funding source is clearly needed to organize effective protection. Therefore, if the government does not have an interest in investing in preservation 
of forests exclusively for educational purposes, what about to preserve forests exclusively to sustain a supply of resonance wood? There is a trend in the most-developed regions of the world to increase the area of their strictly protected forests. Thus setting apart a few beech-fir-spruce forest stands faced north and with the characteristics of karst terrain at the Balkan's Dinaric Mountains as strictly protected areas would likely not cause a noticeable immediate loss from the regular income for the forest enterprises. Also, the forest enterprises would strictly protect and carefully manage such forest stands foreseeing the yield of resonance wood in future. Such forest reserves would be managed for their main purpose to support our cultural assets. A selective cut could be permitted inside of the "harmony-forests" but it should be well balanced and adopted to mimic natural dying processes of the trees. The forest reserve Lom has been illegally-logged for some time and the illegal-logging is likely still ongoing. So why not consider also protecting the forest reserve Lom as a legally certified source of resonance wood from spruce? Can that save this exceptionally beautiful forest from illegal use? All these questions cannot be answered here. It is certainly desired that the forest reserve Lomis adequately protected from theft and that the governing bodies very soon come-up with the most appropriate solution in order to preserve the forest for the future generations to enjoy.

\section{Conclusion}

Many factors may be responsible for creating favourable conditions for spruce trees to bear high-quality resonance wood. However, it is believed that four major factors, working together with other unknown factors, have a decisive role: mixed forest environment, topography of the terrain, disturbance regime and age of spruce trees.

The structure and composition of trees in forests is not a static system and it is not known how changes in the climate, soil properties, genetic predispositions and possibly some other unaccounted-for factors will affect the growth of spruce trees in the future. However, it is believed that forest management can preserve important cultural heritage by planning and setting aside appropriate forest areas to foster production of resonance wood from spruce. Furthermore, adopting forest certification and supply chains for the purpose of sustaining supplies of resonant wood for acoustic musical instruments is also seen very important. That will likely get a positive feedback from the general public as well as from the makers of traditional musical instruments.

Forest management heavily favouring the "industrial production of wood" only worsens any act toward sustaining the production of the resonance wood of naturally high quality. It was to expect that the musical instruments industry would increasingly shift toward new materials and techniques in order to produce instruments able to reproduce our favourite sound. It should be emphasized that the shift by the musical instruments industry toward new materials and techniques is not seen as a problem if the continuation of our cultural assets based on resonance wood of naturally high quality is ensured. Strict preservation of appropriate forests in their naturally appropriate sites is likely to yield certain amounts of resonant wood. However, it cannot be claimed that such practices will be economically viable. On the other hand, in order to preserve the assets of our traditional musical culture it is strongly advised to preserve and act toward preserving forests having a potential to yield resonance wood of traditionally high quality.

Setting aside a few forest stands from regular harvesting operations will still serve to raise income from non-timber forest products while people would be able to enjoy in the amenities of old-growth naturally regenerated forests. The suggestion on how to sustain supplies of certain amounts of resonance wood from spruce is given from the stand-point of a forester. However, the final solution would require heavily engaging a policy and the decision makers should give their final word.

The challenge to sustain a supply of high quality resonance wood, in particular from spruce, is very high. Knowledge is highly limited with almost a complete lack of funds to support a forest research, or the research is conducted independently by the giant corporations involved in the acoustic musical instruments industry which usually doesn't share information. However, refraining from an open dissemination of information would presumably keep the public eyes closed and leave the resources to illegal-loggers or to unscrupulous elements inside of the acoustic musical instruments industry. Creating conditions suitable for a sustainable production of high-quality resonance wood from spruce is believed to bring a positive attitude toward the industry, and the culture which such largely depends on the endangered natural resource will thrive.

Sustaining forests that produce resonance wood is effective in sustaining our cultural as well as natural heritage. This broad approach can also be considered for other culturally-important natural products.

\section{Acknowledgements}

I'm grateful to Benjamin McLellan for his valuable advice.

\section{References}

[1] Wegst UGK. Wood for sound. Am J Bot 200693(10): 1439-1448.

[2] Gug R. Choosing Resonant Wood. Strad 1991102(1209): 6o-64.

[3] Fukada E.Vibrational study of the wood used for the sound boards of pianos. Nature1950 166: 772-773.

[4] Ono T, Norimoto M.On physical criteria for the selection of wood for soundboards of musical instruments. RheolActa 198423: 652-656.

[5] Spycher M, Schwarze FWMR, Steiger R.Assessment of resonance wood quality by comparing its physical and histological properties. Wood SciTechnol 200742: 325-342.

[6] Buksnowitz C,Teischinger A, Müller U, Pahler A, Evans R.Resonance wood [Piceaabies (L.) Karst.] - evaluation and prediction of violin makers' quality-grading. J AcoustSoc Am 2006121(4): 2384-2395.

[7] Szewczyk J, Szwagrzyk J, Muter E.Tree growth and disturbance dynamics in old-growth subalpine spruce forests of the Western Carpathians. Can J For Res 201141: 938-944.

[8] Matić S. The impact of Site Changes and management Methods on Dieback of Common Spruce (Piceaabies Karst.) in Croatia. Croat J ForEng 201132(1): 7-17.

[9] Klopcic M, Boncina A.Stand dynamics of silver fir ( Abies alba Mill. ) European beech ( Fagussylvatica L.) forests during the past century: a decline of silver fir?. Forestry 201184(3): 259-271.

[10] Pintarić K. Forestry and forest reserves in Bosnia and Herzegovina. In: Diaci J, editors.Virgin forests and forest reserves in Central and East European countries: history, present status and future development, Ljubljana: Biotechnical Faculty; 1999, p. 1-15.

[11] MlinšekD. Forestry in Slovenia as a proof of nature's unpredictability, bifurcation, etc..In: Diaci J, editors.Virgin forests and forest reserves in Central and East European countries: history, present status and future development, Ljubljana: Biotechnical Faculty; 1999, p. 121-132.

[12] Visnjic Ć, Vojnikovic S, Ioras F, Dautbasic M, Abrudan IV, Gurean D, Lojo A, Trestic T, Ballian D, Bajric M. Virgin Status Assessment of Plješevica Forest in Bosnia - Herzegovina. Not Bot HortiAgrobo 200937(2): 22-27.

[13] Firm D, Nagel TA, Diaci J.Disturbance history and dynamics of an oldgrowth mixed species mountain forest in the Slovenian Alps. Forest EcolManag2009257: 1893-1901.

[14] Potočić Z. ŠumarskaEnciklopedija LeksikografskizavodMiroslavKrleža; 1980, p. 166-169.

[15] Nagel TA, Svoboda M, Rugani T,Diaci J. Gap regeneration and replacement patterns in an old-growth Fagus-Abies forest of BosniaHerzegovina. Plant Ecol 2010208: 307-318.

[16] Ljubojević S, Marčeta D. The level of forest exploitation in protected areas of Republic of Srpska. Bulletin Faculty of Forestry - University of Banja Luka 20077: 23-50. 
[17] Bond CW. Wood anatomy in relation to violin tone. J I Wood Sci1976 7(39): 22-26.

[18] Bourne LB. Dermatitis from Mansonia wood. Brit J Ind Med1956 13(55): $55-58$.

[19] Hori R, Müller M, Watanabe U, Lichtenegger HC, Fratzl P, Sugiyama J. The importance of seasonal differences in the cellulose microfibril angle in softwoods in determining acoustic properties. J Mater Sci 200237: 4279-4284.

[20]Yano H, Furuta Y, Nakagawa H. Materials for guitar back plates made from sustainable forest resources. J AcoustSoc Am 1996101(2): 1112-1119.

[21] Yano H, Kajita H, Minato K.Chemical treatment of wood for musical instruments. J AcoustSoc Am 199496(6): 3380-3391.

[22] Yano H, Hirose A, Inaba S. High-strength wood-based materials. J Mater SciLett1997 16: 1906-1909.

[23] Schwarze FWMR, Spycher M, Fink S. Superior wood for violins - wood decay fungi as a substitute for cold climate. New Phytol2oo8 179: 10951104.

[24] Kräuchi N, Brang P,Schönenberger W. Forests of mountainous regions: gaps in knowledge and research needs. Forest EcolManag 2000132: 7382.

[25] Burckle L,Grissino-Mayer HD.Stradivari, violins, tree rings, and the Maunder Minimum: a hypothesis. Dendrochronologia 200321(1): 41-45.

[26]Wilson R, Topham J.Violins and climate. TheorApplClimatolzoo4 77: 924.

[27] Barlow CY, Edwards PP, Millward GR, Raphael RA, Rubio DJ.Wood treatment used in Cremonese instruments. Nature1988 332: 313.

[28] Nagyvary J, DiVerdi JA, Owen NL,Tolley HD. Wood used by Stradivari and Guarneri. Naturezoo6 444: 565.

[29]Echard J-P, Bertrand L, von Bohlen A, Le Hô A-S, Paris C, Bellot-Gurlet L, Soulier B, Lattuati-Derieux A, Thao S, Robinet L, Lavédrine B,Vaiedelich S.The Nature of the Extraordinary Finish of Stradivari's Instruments. AngewChemInt Ed2010 49: 197-201.

[30] Houtsma AJM. Pitch and Timbre: Definition, Meaning and Use. J New Music Res1997 26: 104-115.

[31] Obataya E, Ono T, Norimoto M.Vibrational properties of wood along the grain. J Mater Scizooo 35: 2993-3001.

[32] Farrell EP, Fuhrer E, Ryan D, Andersson F, Huttl R, Piussi P.European forest ecosystems: building the future on the legacy of the past. Forest EcolManag 2000132: 5-20.

[33] Motta R, Berretti R, Castagneri D, Dukić V, Garbarino M, Govedar Z, Lingua E, Maunaga Z, Meloni F. Toward a definition of the range of variability of central European mixed Fagus-Abies-Picea forests: the nearly steady-state forest of Lom (Bosnia and Herzegovina). Can J Forest Res 201141: 1871-1884.

[34] Wermelinger B.Ecology and management of the spruce bark beetle Ipstypographus - a review of recent research. Forest EcolManagzoo4 202: 67-82.

[35] Panayotov M, Kulakowski D, Laranjeiro DS, Bebi P. Wind disturbances shape old Norway spruce-dominated forest in Bulgaria. Forest EcolManag 2011262: 470-481.

[36] Szewczyk J, Szwagrzyk J, Muter E. Tree growth and disturbance dynamics in old-growth subalpine spruce forests of the Western Carpathians. Can J For Res 201141: 938- 944.

[37] Bottero A, Garbarino M, Dukić V, Govedar Z, Lingua E, Nagel TA, Motta R.Gap-Phase Dynamics in the Old-Growth Forest of Lom, Bosnia and Herzegovina. Silva Fenn 201145(5): 875-887. 